Original Article

\title{
Immediate effects of ankle eversion taping on dynamic and static balance of chronic stroke patients with foot drop
}

\author{
Young Jun Shin, PT, MS'1), So Min KIm, PT, MS'1), Hyun Sung KIm, PT, MS 1)** \\ 1) Department of Physical Therapy, College of Rehabilitation Sciences, Daegu University: Jillyang, \\ Gyeongsan, Gyeongbuk 712-714, Republic of Korea
}

\begin{abstract}
Purpose] This study evaluates the immediate effect of ankle eversion taping on dynamic and static balance of chronic stroke patients with foot drop. [Subjects and Methods] This study was conducted with nine subjects who were diagnosed with stroke. A cross-over randomized design was used. Each subject performed three interventions in a random order. Subjects were randomly assigned to an ankle everion taping, placebo taping, and no taping. For dynamic and static balance, ability was measured using BIO Rescue. Limit of stability, sway length and sway speed for one minute were measured. [Results] The Limit of Stability, Sway length and Sway speed differed significantly among the three different taping methods. [Conclusion] We conclude that ankle eversion taping that uses kinesiology tape instantly increases the dynamic and static balance ability of chronic stroke patients with foot drop.

Key words: Ankle eversion taping, Stroke, Foot drop
\end{abstract}

(This article was submitted Jan. 31, 2017, and was accepted Mar. 14, 2017)

\section{INTRODUCTION}

Generally, stroke patients have severe disabilities such as hemiplegia, abnormal walking, and reduced balance ability ${ }^{1)}$. In particular, the decrease of balance ability causes a lot of difficulty in performing activities of daily living, and in severe cases, stroke patients may be exposed to the risk of falling ${ }^{2}$. Therefore, restoration of balance ability is one of the most important clinical goals in the rehabilitation of stroke patients ${ }^{3}$. Generally, lack of balance ability is caused by various causes, such as spasticity ${ }^{4}$, muscle strength weakness ${ }^{4}$, and hemiplegia ${ }^{5)}$, but foot drop, which is caused by stiffness of plantar flexors, weakness of dorsiflexors, and increased spasticity, is one of the most important causes ${ }^{6}$. Therefore, foot drop treatment is often a common approach used to restore balance ability clinically, and the most representative treatments are the Functional Electrical Stimulation (FES) and Ankle Foot Orthosis (AFO) ${ }^{7}$. Recently, a robotic device ${ }^{8)}$ is used to correct foot drop in some cases, but the three treatment methods mentioned above (FES, AFO, and a robotic device) are expensive, inconvenient to carry, and not aesthetically good in appearance.

To overcome these drawbacks, taping that is easily applicable and inexpensive is widely used as an alternative treatment method. The purpose of this study was to evaluate the immediate effects of application of ankle eversion taping using kinesiology tapes on the dynamic and static balance of patients with foot drop after stroke.

\section{SUBJECTS AND METHODS}

9 subjects were recruited and all subject met the inclusion criteria for study procedure. Subjects were recruited from D rehabilitation center, after providing informed, written consent. Written informed consent according to the ethical standards

\footnotetext{
*Corresponding author. Hyun Sung Kim (E-mail: khs1334@naver.com)

(C)2017 The Society of Physical Therapy Science. Published by IPEC Inc.

This is an open-access article distributed under the terms of the Creative Commons Attribution Non-Commercial No Derivatives (by-nc-nd) License $<$ https://creativecommons.org/licenses/by-nc-nd/4.0/>.
} 
of the Declaration of Helsinki was provided by all subjects prior to participation, and all agree to participate in this study. Subjects include 5 males and 4 females; Stroke types included 3 hemorrhagic and 6 infarction. The mean age of the subjects was $64.78 \pm 8.12$ years, height was $164.78 \pm 10.58 \mathrm{~cm}$, weight was $64.22 \pm 17.09 \mathrm{~kg}$, and years since onset $7.41 \pm 1.87$ years. The enrollment criteria applied were as follows: (1) Index stroke $>6$ months prior in women or men with foot drop (equinovarus deformity), (2) Brunnstrom's stage of motor recovery for the affected lower limb range of 3-5, (3) residual hemiparetic gait deficits, operationally defined as reduced stance phase in the paretic leg and ambulatory with or without any assistive device $^{9}$, (4) ability to understand and follow simple verbal instructions, (5) independent gait ability to walk at least $15 \mathrm{~m}$ without assistance, (6) no disability in visual, auditory, and vestibular organs, (7) no history of orthopedic diseases, such as contracture, fracture, or arthritis in lower limbs, and (8) a Mini-Mental State Examination score greater than 24/30 ${ }^{10}$.

Exclusion criteria were as follows: (1) neurological problems other than stroke that would interfere with gait and balance control, (2) pain, limited motion, or weakness in the non-paretic lower extremity that affected performance of daily activities (by self-report), and (3) have taping side effects such as skin redness.

A cross-over randomized design was used. Each subject performed three interventions in random order. Subjects were randomly assigned to a ankle eversion taping, placebo taping, and no taping. Subject characteristics and all outcome measures obtained before and after treatment were assessed by Physician 1, who was blinded to treatment allocations. Intervention was performed in a closed room by Physician 2, who was not involved in subject assessment. Both physicians were instructed not to communicate with subjects about study goals or treatments.

This study used kinesiology tape (Kinematics Tex, SPOL Co., Ltd., Seoul, Korea) with elasticity. The patient is seated in a comfortable position on a table that is high enough to prevent the feet from touching the ground, while the therapist applies the tape on the damaged ankle stretched with a tension of $70-80 \%$.

Ankle Eversion Taping (AET) consists of two stages ${ }^{11)}$. The first stage is posterior talar gliding taping to increase the dorsiflexion of the ankle. The second stage is eversion taping for the eversion of ankle. It sets the patient's ankle in a slightly eversed state and begins from $5 \mathrm{~cm}$ above the outer malleolus, passes through the back side and down of inner malleolus and wraps up the sole from the inside to outside. This stage applies the Kinesiology tape twice, with approximately $50 \%$ overlapping. Since the patients have a disability in the equino-varus deformity of foot due to stiffness of plantar flexors, weakness of dorsiflexors and increased spasticity, taping is done twice in order to reinforce the inversion of ankle through eversion taping application.

Placebo taping can be classified into two stages ${ }^{12)}$. The first stage begins from the inner malleolus, and it is applied up to the inner middle point of the lower limb. The second stage begins from the outer malleolus up to the outer middle point of the lower limb.

For postural adjustment ability, center of pressure (COP) was measured using BIORescue (RM Ingenierie, Rodes, France). The elements measured included the sway length and sway speed to evaluate the static balance ability; low value indicated good balance ability. Also, the element measured included the Limit of stability (LOS) to evaluate the dynamic balance ability; high value indicated good balance ability. Limit of stability (LOS), sway length, and sway speed were measured for one minute.

Statistical analysis was performed using SPSS (SPSS Inc. Released 2009. PASW Statistics for Windows, Version 18.0. SPSS Inc., Chicago, IL, USA). General characteristics were analyzed using descriptive statistics and results are reported as means and standard deviations. One-way repeated ANOVA was used for the group analysis, and the post-hoc Tukey test was used to correct for multiple comparisons. Null hypotheses of no difference were rejected if $\mathrm{p}$-values were less than 0.05 .

\section{RESULTS}

AET showed significantly difference of Limit of Stability, Sway length, and Sway speed than NT and PT (p<0.05) (Table 1).

Table 1. Comparison of the limit of stability (LOS), sway length, sway speed among the three conditions $(\mathrm{n}=9)$

\begin{tabular}{lcccc}
\hline & \multicolumn{3}{c}{ Mean \pm SD } & \multirow{2}{*}{ Post-hoc } \\
\cline { 2 - 4 } & NT & PT & AET & \\
\hline $\begin{array}{l}\text { LOS } \\
(\mathrm{mm})\end{array}$ & $3,185.6 \pm 2,149.4$ & $3,569.3 \pm 2,431.6$ & $4,362.0 \pm 2,700.3$ & $\begin{array}{l}\text { AET }>\text { PT } \\
\text { AET }>\text { NT }\end{array}$ \\
$\begin{array}{l}\text { Sway length } \\
\text { (cm) }\end{array}$ & $36.2 \pm 11.4$ & $33.0 \pm 8.5$ & $28.9 \pm 8.2$ & $\begin{array}{l}\text { AET }>\text { PT } \\
\text { Sway speed } \\
\text { (cm/s) }\end{array}$ \\
\hline
\end{tabular}

NT: no taping; PT: placebo taping; AET: ankle eversion taping 


\section{DISCUSSION}

This study was conducted to evaluate the immediate effects of Ankle Eversion Taping with a kinesiology tape on the dynamic and static balance of chronic stroke patients with foot drop. After the application of ankle eversion taping, the dynamic and static balance abilities of chronic stroke patients were significantly improved. In addition, sway length and sway speed (measures of static balance) and limits of stability (LOS) (a measure of dynamic balance) were statistically significantly improved, compared with the other two interventions (placebo taping and no taping).

This study suggests that there are several mechanisms for the effects of kinesiology taping in improving the balance ability of chronic stroke patients. First, ankle eversion taping is generally a mechanical taping method to correct the alignment, not the way to apply a kinesiology tape to muscles. The effect of kinesiology taping on correcting this alignment has been reported in many studies. Han et al. ${ }^{13)}$ reported a mechanical effect of using a kinesiology tape on a rounded shoulder posture. Lee et al. ${ }^{14)}$ demonstrated that a change in the pelvic angle can be caused by applying the Anterior Pelvic Tilt Taping (APTT), a mechanical method, to the slump sitting of the workers who work sitting for a long time. Another mechanism can be described as a methodological part of the AET. As mentioned earlier, the AET used in this study employed the method suggested by Lee et al. ${ }^{11)}$ as a mechanical taping method. This AET method was applied to patients with ankle inversion sprain injury and it was shown to improve functional dynamic balance.

The current study has several limitations. First, the small sample size may have influenced certain variables and influenced the results. Therefore, these results cannot be generalized to all subjects who have ankle instability. Second, the current experiment is a crossover design, which makes it difficult to observe the learning effect of taping.

Further studies, including a long-term follow-up assessment, are needed to evaluate the long-term benefits of balance taping. In conclusion, the application of Ankle Eversion Taping that uses kinesiology tape instantly increased the dynamic and static balance ability of chronic stroke patients with foot drop. Therefore AET can be a useful alternative to treat chronic stroke patients with foot drop.

\section{REFERENCES}

1) Jongbloed L: Prediction of function after stroke: a critical review. Stroke, 1986, 17: 765-776. [Medline] [CrossRef]

2) Niam S, Cheung W, Sullivan PE, et al.: Balance and physical impairments after stroke. Arch Phys Med Rehabil, 1999, 80: 1227-1233. [Medline] [CrossRef]

3) Cho HY, Kim JS, Lee GC: Effects of motor imagery training on balance and gait abilities in post-stroke patients: a randomized controlled trial. Clin Rehabil, 2013, 27: 675-680. [Medline] [CrossRef]

4) Byun SD, Jung TD, Kim CH, et al.: Effects of the sliding rehabilitation machine on balance and gait in chronic stroke patients-a controlled clinical trial. Clin Rehabil, 2011, 25: 408-415. [Medline] [CrossRef]

5) Vearrier LA, Langan J, Shumway-Cook A, et al.: An intensive massed practice approach to retraining balance post-stroke. Gait Posture, 2005 , 22: 154-163. [Medline] [CrossRef]

6) Burridge JH, McLellan DL: Relation between abnormal patterns of muscle activation and response to common peroneal nerve stimulation in hemiplegia. J Neurol Neurosurg Psychiatry, 2000, 69: 353-361. [Medline] [CrossRef]

7) Laufer Y, Ring H, Sprecher E, et al.: Gait in individuals with chronic hemiparesis: one-year follow-up of the effects of a neuroprosthesis that ameliorates foot drop. J Neurol Phys Ther, 2009, 33: 104-110. [Medline] [CrossRef]

8) Cho DY, Park SW, Lee MJ, et al.: Effects of robot-assisted gait training on the balance and gait of chronic stroke patients: focus on dependent ambulators. J Phys Ther Sci, 2015, 27: 3053-3057. [Medline] [CrossRef]

9) Macko RF, Ivey FM, Forrester LW, et al.: Treadmill exercise rehabilitation improves ambulatory function and cardiovascular fitness in patients with chronic stroke: a randomized, controlled trial. Stroke, 2005, 36: 2206-2211. [Medline] [CrossRef]

10) Folstein MF, Folstein SE, McHugh PR: "Mini-mental state". A practical method for grading the cognitive state of patients for the clinician. J Psychiatr Res, 1975, 12: 189-198. [Medline] [CrossRef]

11) Lee SM, Lee JH: Effects of ankle eversion taping using kinesiology tape in a patient with ankle inversion sprain. J Phys Ther Sci, 2016, 28: 708-710. [Medline] [CrossRef]

12) Kim BJ, Lee JH, Han JT: The immediate effect of ankle balance taping using kinesiology tape on the weight-bearing ankle dorsiflexion range of motion and the dynamic balance in asymptomatic subjects. J Korean Soc Phys Med, 2014, 9: 263-270. [CrossRef]

13) Han JT, Lee JH, Yoon CH: The mechanical effect of kinesiology tape on rounded shoulder posture in seated male workers: a single-blinded randomized controlled pilot study. Physiother Theory Pract, 2015, 31: 120-125. [Medline] [CrossRef]

14) Lee JH, Yoo WG: The mechanical effect of anterior pelvic tilt taping on slump sitting by seated workers. Ind Health, 2011, 49: 403-409. [Medline] [CrossRef] 